\title{
Mendidik Anak Menjadi Anak Sholeh
}

Andi Ombong Sapada, ST., M.Si.

Dosen Sekolah Tinggi Agama Islam Darud Dakwah wal Irsyad (STAI DDI) Kota Makassar

Email: andiosapada@gmail.com

\begin{abstract}
Abstrak
Anak merupakan harta yang paling berharga dalam kehidupan berumah tangga. Anak merupakan titipan dari Allah swt untuk dijaga, dan dididik sebagai penolong di hari kemudian. Mendidik anak adalah suatu keharusan terlebih untuk menjadi anak sholeh dan sholehah. Maka diperlukan jurus atau konspe dalam mendidikan anak untuk menjadi anak yang berbakti dan shaoleh.
\end{abstract}

Kata Kunci: Mendidik, Anak, Sholeh.

\section{Pendahuluan}

Segala puji bagi Allah, shalawat dan salam semoga tercurah kepada Rasulullah, keluarga dan para sahabatnya. Masih dalam rangkaiannya, kami ditugaskan untuk memberikan caramah. Kebetulan materi pengajian seputar pilar-pilar penting dalam mendidik anak. Karena banyaknya permintaan dari jama'ah, bahan materi tersebut kami kumpulkan dalam bentuk makalah yang kami beri judul "Jurus Jitu Mendidik Anak". Tentu masih terlalu jauh dari format sempurna, namun semoga yang sederhana ini bisa bermanfaat bagi kita semua.

\section{Pembahasan}

Ilmu merupakan kebutuhan primer setiap insan dalam setiap lini kehidupannya, termasuk dalam mendidik anak (Harmaini, H., Shofiah, V., \& Yulianti, A. 2015). Bahkan kebutuhan dia terhadap ilmu dalam mendidik anak, melebihi kebutuhannya terhadap ilmu dalam menjalankan pekerjaannya.

Namun, realita berkata lain. Rupanya tidak sedikit di antara kita mempersiapkan ilmu untuk kerja lebih banyak daripada ilmu untuk menjadi orangtua. Padahal tugas menjadi orangtua dua puluh empat jam sehari semalam, termasuk saat tidur, terjaga serta antara sadar dan tidak. Sementara tugas kita dalam pekerjaan, hanya sebatas jam kerja.

Betapa banyak suami yang menyandang gelar bapak hanya karena istrinya melahirkan. Sebagaimana banyak wanita disebut ibu semata-mata karena dialah yang melahirkan. Bukan karena mereka menyiapkan diri menjadi orangtua. Bukan pula karena mereka memiliki kepatutan sebagai orangtua.

Padahal, menjadi orangtua sebagai bentuk realisasi bagi manusia yang diberi tanggung jawab oleh Allah menjadi Khalifah yang harus berbekal ilmu yang memadai. Sekadar memberi mereka uang dan memasukkan di sekolah unggulan, tak cukup untuk membuat anak kita menjadi manusia unggul. Sebab, banyak hal yang tidak bisa dibeli dengan uang.

Uang memang bisa membeli tempat tidur yang mewah, tetapi bukan tidur yang lelap. Uang bisa membeli rumah yang lapang, tetapi bukan kelapangan hati untuk tinggal di dalamnya (Nurjannah, 2019). Uang juga bisa membeli pesawat televisi yang sangat besar untuk menghibur anak, tetapi bukan kebesaran jiwa untuk memberi dukungan saat mereka terempas. Betapa banyak anak-anak yang rapuh jiwanya, padahal mereka tinggal di rumah-rumah yang kokoh bangunannya. Mereka mendapatkan apa saja dari orangtuanya, kecuali perhatian, ketulusan dan kasih saying. Banyak jenis ilmu yang dibutuhkan orangtua dalam mendidik anaknya (Ezrat, 2018). Mulai dari ilmu agama dengan berbagai varianya, hingga ilmu cara berkomunikasi dengan anak. Anak juga perlu mendapatkan Pendidikan sastra dalam 
menciptakan kesadaran dalam bernarasi sehingga tercipta komnikasi yang efektif (Zulkifli, 2020).

Jenis ilmu agama pertama dan utama yang harus dipelajari orangtua adalah akidah (Nurhayati, 2014). Sehingga ia bisa menanamkan akidah yang lurus dan keimanan yang kuat dalam jiwa anaknya. Nabi shallallahu'alaihiwasallam mencontohkan bagaimana membangun pondasi tersebut dalam jiwa anak, dalam salah satu sabdanya untuk Ibnu Abbas radhiyallahu'anhuma,

Artinya:

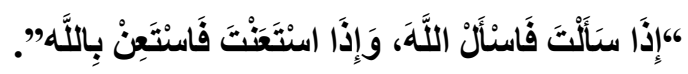

"Jika engkau memohon, mohonlah kepada Allah. Dan jika engkau meminta pertolongan, mintalah kepada Allah". HR. Tirmidzi dan beliau berkomentar, "Hasan sahih".

Selanjutnya ilmu tentang cara ibadah, terutama shalat dan cara bersuci. Demi merealisasikan wasiat Nabi shallallahu'alaihiwasallam untuk para orangtua,

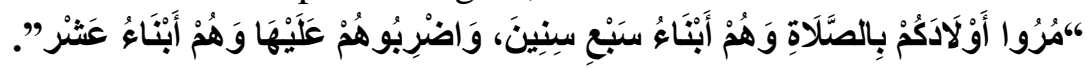

Artinya:

"Perintahkanlah anak-anak kalian untuk shalat saat berumur tujuh tahun, dan pukullah jika enggan saat mereka berumur sepuluh tahun". HR. Abu Dawud dan dinilai sahih oleh Syaikh al-Albany.

Semoga pemaparan singkat di atas bisa menggambarkan pada kita urgensi ilmu dalam mendidik anak. Sehingga diharapkan bisa mendorong kita untuk terus mengembangkan diri, meningkatkan pengetahuan kita, menghadiri majlis taklim, membaca buku-buku panduan pendidikan. Pendidikan akhlak remaja bagi keluarga kelas menengah perkotaan menajdi salah satu contoh bagi pendidikan untuk orang tua (Munthoha, P. Z., \& Wekke, I. S. 2017). Agar kita betul-betul menjadi orangtua yang sebenarnya, bukan sekedar orang yang lebih tua dari anaknya.

Ikhlas merupakan ruh bagi setiap amalan. Amalan tanpa disuntik keikhlasan bagaikan jasad yang tak bernyawa. Termasuk jenis amalan yang harus dilandasi keikhlasan adalah mendidik anak adalah Rawat dan didik anak dengan penuh ketulusan dan niat ikhlas sematamata mengharapkan keridhaan Allah ta'ala.

Canangkan niat semata-mata untuk Allah dalam seluruh aktivitas edukatif, baik berupa perintah, larangan, nasehat, pengawasan maupun hukuman (Syamsiyah, 2016). Iringilah setiap kata yang kita ucapkan dengan keikhlasan.Bahkan dalam setiap perbuatan yang kita lakukan untuk merawat anak, entah itu bekerja membanting tulang guna mencari nafkah untuknya, menyuapinya, memandikannya hingga mengganti popoknya, niatkanlah semata karena mengharap ridha Allah.

Ikhlas memiliki dampak kekuatan yang begitu dahsyat. Dengan keikhlasan anak kita akan mudah diatur. Jangan pernah meremehkan perhatian dan pengamatan anak kita (Machdi, I. F., \& Harmanto, H. 2015). Anak yang masih putih dan bersih dari noda dosa akan begitu mudah merasakan suasana hati kita.Dia bisa membedakan antara tatapan kasih sayang dengan tatapan kemarahan, antara dekapan ketulusan dengan pelukan kejengkelan, antara belaian cinta dengan cubitan kesal.

Di zaman serba teknologi sekarang ini, media sosial menjadi salah satu teknologi yang dapat mempengaruhi kehidupan anak. Dengan media sosial, banyak pengetahuan agama yang dapat diberikan secara mudah dan praktis (Sainuddin, 2020). Sabar merupakan salah satu syarat mutlak bagi mereka yang ingin berhasil mengarungi kehidupan di dunia. Kehidupan yang tidak 
lepas dari susah dan senang, sedih dan bahagia, musibah dan nikmat, menangis dan tertawa, sakit dan sehat, lapar dan kenyang, rugi dan untung, miskin dan kaya, serta mati dan hidup.

Di antara episode perjalanan hidup yang membutuhkan kesabaran ekstra adalah masamasa mendidik anak. Bentuk dan isi serta cara cara pendidikan di dalam keluarga akan selalu mempengaruhi tumbuh dan berkembangnya watak, budi pekerti dan kepribadian tiap-tiap manusia. Sebab rentang waktunya tidak sebentar dan seringkali anak berperilaku yang tidak sesuai dengan harapan kita.

1. Sabar dalam membiasakan perilaku baik terhadap anak (Huda, 2018). Anak bagaikan kertas yang masih putih, tergantung siapa yang menggoreskan lukisan di atasnya. Rasulullah shallallahu'alaihiwasallam menggambarkan hal itu dalam sabdanya,

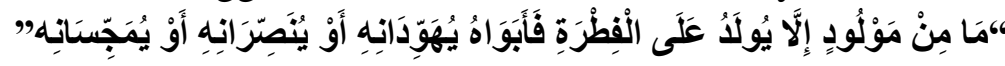

Artinya:

"Setiap bayi lahir dalam keadaan fitrah. Orang tuanya lah yang akan menjadikan ia Yahudi, Nasrani atau Majusi”. (HR. Bukhari dan Muslim dari Abu Hurairah)

Andaikan sejak kecil anak dibiasakan berperilaku baik, mulai dari taat beribadah hingga adab mulia dalam keseharian, insyaAllah hal itu akan sangat membekas dalam dirinya. Sebab mendidik di waktu kecil bagaikan mengukir di atas batu.

Mengukir di atas batu membutuhkan kesabaran dan keuletan, namun jika ukiran tersebut telah jadi niscaya ia akan awet dan tahan lama.

2. Sabar manakala emosi memuncak (Diana, 2018). Hendaknya kita tidak memberikan sanksi atau hukuman pada anak ketika emosi kita sedang memuncak. Pada saat emosi kita sedang tinggi, apa pun yang keluar dari mulut kita, cenderung untuk menyakiti dan menghakimi, tidak untuk menjadikan anak lebih baik. Yang seyogyanya dilakukan adalah: bila kita dalam keadaan sangat marah, segeralah menjauh dari anak. Pilihlah cara yang tepat untuk menurunkan amarah kita dengan segera. Bisa dengan mengamalkan tuntunan Nabi shallallahu'alaihiwasallam; yakni berwudhu. Ingat, prinsip hukuman adalah untuk mendidik bukan untuk menyakiti.

Sebesar apapun usaha orangtua dalam merawat, mendidik, menyekolahkan dan mengarahkan anaknya, andaikan Allah ta'ala tidak berkenan untuk menjadikannya anak salih, niscaya ia tidak akan pernah menjadi anak salih (Firdaus, 2016). Hal ini menunjukkan betapa besar kekuasaan Allah dan betapa kecilnya kekuatan kita. Ini jelas memotivasi kita untuk lebih membangun ketergantungan dan rasa tawakkal kita kepada Allah jalla wa 'ala. Dengan cara, antara lain, memperbanyak menghiba, merintih, memohon bantuan dan pertolongan dari Allah dalam segala sesuatu, terutama dalam hal mendidik anak. Adalah menjadi kewajiban bagi orang tua agar dapat memotivasi anak ke jalan kebaikan terutama sesuai dengan ajaran agama Islam, ada banyak cara untuk beribadah kepada Allah SWT seperti sholat, puasa, dan menuntut ilmu.

Sejak Anda melakukan proses hubungan suami istri telah disyariatkan untuk berdoa demi kesalihan anak Anda. Rasulullah shallallahu'alaihiwasallam mengingatkan,

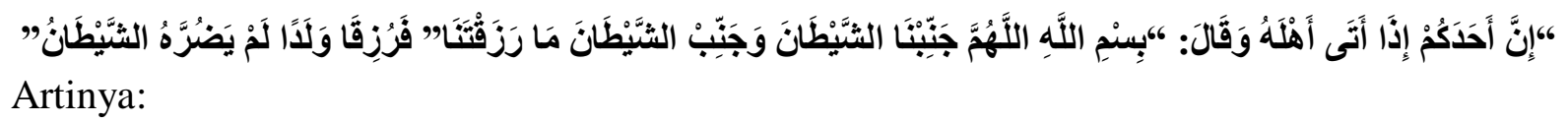

"Jika salah seorang dari kalian sebelum bersetubuh dengan istrinya ia membaca "Bismillah, allôhumma jannibnasy syaithôn wa jannibisy syaithôna mâ rozaqtanâ" (Dengan nama Allah. Ya Allah jauhkanlah kami dari setan dan jauhkanlah setan dari 


\section{Kesimpulan}

Dalam mendidik anak dibutuhkan kesabaran dan penuh tanggung jawab. Anak sejatinya adalah titpan dari Allah swt untuk dijaga sebaik-baiknya. Dalam mendidik anak dibutuhkan jurus jitu sehingga yang sesuai dengan tuntunan al-Qur'an dan hadis sehingga menjadi anak yang sholeh dan sholehah dan berbakti kepada orang tua, agama bangsa dan negara.

\section{Daftar Pustaka}

Diana, R. R. (2018). Pengendalian Emosi Menurut Psikologi Islam. Unisia, 37(82), 41-47.

Rifqi, N., Fajrin, M. F., \& Arsyam, M. (2021). Ibadah Sebagai Aspek Ritual Ummat Islam.

Erzad, A. M. (2018). Peran Orang Tua Dalam Mendidik Anak Sejak Dini Di Lingkungan Keluarga. ThufuLA: Jurnal Inovasi Pendidikan Guru Raudhatul Athfal, 5(2), 414-431.

Firdaus, S. (2016). Peranan Orang Tua Dalam Mendidik Kecerdasan Emosional Anak Usia 6-12 Tahun Dalam Persepektif Pendidikan Islam.

Arsi, A., Fail, W. O. N., \& Arsyam, M. (2021). Membangun Keluarga Yang Islami.

Harmaini, H., Shofiah, V., \& Yulianti, A. (2015). Peran ayah dalam mendidik anak. Jurnal psikologi, 10(2), 80-85.

Hizriyani, R. (2019). IMPLEMENTASI PEREMPUAN TERHADAP PENDIDIKAN ANAK USIA DINI. $A L$-WARDAH, 12(1), 49-58.

Huda, H. (2018). OPTIMALISASI PENDIDIKAN AKHLAK PADA ANAK USIA SEKOLAH DASAR. TARLIM: JURNAL PENDIDIKAN AGAMA ISLAM, l(1).

Munthoha, P. Z., \& Wekke, I. S. (2017). Pendidikan Akhlak Remaja bagi Keluarga Kelas Menengah Perkotaan. Cendekia: Jurnal Kependidikan Dan Kemasyarakatan, 15(2), 241-263.

Nurhayati, L. (2014). Pengaruh Pola Asuh Orang Tua terhadap Prestasi Belajar Siswa pada Mata Pelajaran Aqidah Akhlak di Madrasah Ibtidaiyah (MI) Miftahul Falah Kayen Kademangan Blitar.

Nurjannah, A. (2019). Implementasi hak khiyar dalam jual beli terhadap slogan barang yang sudah dibeli tidak dapat dikembalikan (Studi Kasus Pada Toko Grosir dan Eceran Binti Sholikah) (Doctoral dissertation, IAIN Metro).

Sapada, A. O., \& Arsyam, M. (2020). Ilmu Pengetahuan dan Teknologi Menurut Pandangan Islam.

Sainuddin, I. H., S. (2020, July 27). Dakwah di Era Sosial Media. https://doi.org/10.31219/osf.io/2jxny

Syamsiyah, S. (2016). MANAJEMAN DAKWAH PRAMUKA PEDULI: Studi Kasus Program Kerja Pemberantasan Sarang Nyamuk (PSN) Di MAN 5 Jakarta (Doctoral dissertation, UNIVERSITAS NEGERI JAKARTA)

Usman, H. A., Arsyam, M., \& Yusuf, M. (2021, January 17). ETIKA PERDAGANGAN DALAM ISLAM. https://doi.org/10.31219/osf.io/q6rbz 